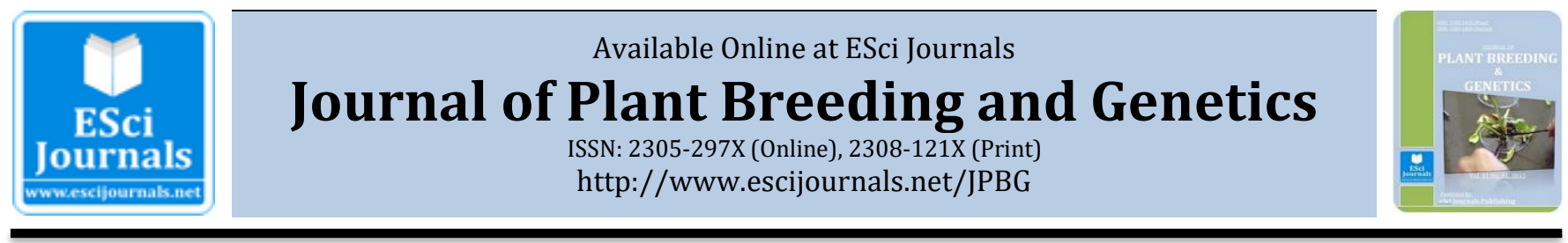

\title{
ASSOCIATION OF AGRO-MORPHOLOGICAL AND OIL TRAITS IN GROUNDNUT (ARACHIS HYPOGAEA L.) CULTIVARS
}

\author{
aZekeria Yusuf*, bHabtamu Zeleke, bWassu Mohammed, cShimelis Hussein, dArno Hugo \\ a Biology Department, Haramaya University, Dire Dawa, Ethiopia. \\ b School of Plant Science, Haramaya University, Dire Dawa, Ethiopia. \\ c Department of Crop Science, University of Kwazulu-Natal, Durban, Republic of South Africa. \\ d Department of Food Science, University of Free State, Bloemfontein, Republic of South Africa.
}

\begin{abstract}
A B S T R A C T
The associations between the traits of interest in plant breeding are commonly evaluated by means of phenotypic, genotypic and environmental correlations, and through path coefficient analysis that shows direct and indirect cause and effect relationship. Sixteen groundnut genotypes (including local check) were evaluated for quantitative parameters. The crop was sown during 2015 wet season across four locations in Ethiopia. The experiment was laid out in Randomized Complete Block Design (RCBD) with two replications. The results indicated that genotypic correlations were higher than the phenotypic and environmental ones. The grain yield (kg/ha) has presented positive and significant genetic correlation with PWP, SWP and 100SW. Genetic correlations of oil content with agro-morphological traits and oil quality parameters were shown that oil content was significant and positively correlated with pod weight per plant (PWP) and seed weight per plant (SWP) showing that possibility of indirect selection for oil content through these traits. The path analysis based on genotypic correlation in the present study was shown that selection for oil content trait is effective through OY, GY, NMP and NSPOD. Furthermore, the path analysis has shown that breeding for high 0/L ratio can be conducted through selection for AGBP, NSPOD, NSP, oil content, TPUS/TS or oleic acid traits; likewise breeding for oil yield (OY) can be conducted via selection for oil content, NSP, AGBP, NBP or TPUS/TS.
\end{abstract}

Keywords: Genetic correlation, PWP, Oil content, Grain yield, Oil quality, Iodine value, OY, O/L ratio.

\section{INTRODUCTION}

The plant breeder's role in identifying the individual crops that simultaneously meet the desirable traits is not easy, because several of these traits are positive or negatively associated. The associations between the traits of interest in plant breeding are evaluated by means of phenotypic, genotypic and environmental correlations. Phenotypic correlations are directly estimated from the mean phenotypic values in the field, being, therefore, the result of genetic and environmental causes. The genotypic correlation, contrastingly, corresponds to the genetic part of the phenotypic correlation and is used to guide breeding programs because of its heritable nature (Hallauer et

* Corresponding Author:

Email: zakoyusuf@yahoo.com

(C) 2018 ESci Journals Publishing. All rights reserved. al., 2010; Falconer and Mackay, 1996; Cruz, 2001). However, the correlation coefficients, nonetheless their high utility in the quantification of the size and direction of factors or effects in the determination of complex characters, offer only relative importance of the direct and indirect effects of these factors. Solution raised for this limitation is to perform a path analysis because it unfolds the estimated correlations into direct and indirect effects (Falconer and Mackay, 1996). Considering such justifications, this research was planned to identify traits that contribute to grain yield, oil content, oil yield and oil quality in groundnut so as to be used as selection criteria in breeding programs of this crop and to meet the demands of the producers and the agro-industry sector.

\section{MATERIALS AND METHODS}

The experiment was carried out across four locations 
viz Fedis, Mechara (Eastern Ethiopia), Pawe and Guba (locations in Western Ethiopia) in 2015 growing season under rainfed condition. The experimental materials consisted of sixteen groundnut genotypes including local variables and varieties which were released by Ethiopian Institute of Agricultural Research (EIAR) from 1976 to 2012 and Haramaya University. Before starting laboratory experiment moisture content of seeds was reduced to $5 \%$. Total lipid from the seed sample was quantitatively extracted, according to the method of Folch et al. (1957). Iodine value was determined with the Hanus method (Baur and Ensminger, 1977). Fatty acids were transesterified to form methyl esters using $0.5 \mathrm{~N} \mathrm{NaOH}$ in methanol and $14 \% \mathrm{BF}_{3}$ in methanol (Slover and Lanza, 1979). FAMEs from fat were quantified using a Varian 430 flame ionization GC, with a fused silica capillary column, Chrompack CPSIL 88 (100 m length, 0.25 mm ID, $0.2 \mu \mathrm{m}$ film thicknesses). Galaxy Chromatography Software recorded the chromatograms.

The estimated genetic $\operatorname{crg}_{\mathrm{rg}(\mathrm{xy})}$ and phenotypic $r_{\mathrm{p}(\mathrm{xy})}$ correlations between traits $\mathrm{x}$ and y (Holland et al., 2010) are given by:

$\mathrm{E}(\mathrm{MSPV})=\sigma_{\text {exey }}+\mathrm{r} \sigma_{\text {gxgy }} ; \mathrm{E}(\mathrm{MSPe})=\sigma_{\text {exey }}$

$\sigma_{\text {gxgy }}=\frac{\text { MSPv }- \text { MSPgxe }}{\text { re }}$

$r_{g(x y)}=\frac{G \operatorname{cov}_{x y}}{\sqrt{\left(G_{x} \cdot G V_{y}\right)}}$

Where, $\sigma 2 \mathrm{~g}(\mathrm{x}, \mathrm{y})$ or $\sigma_{\text {gxgy }}=$ genetic covariance of traits $\mathrm{x}$ and $y ; r_{g(x y)}=$ genetic correlation; $\mathrm{GCOV}_{\mathrm{XY}}=$ Genotypic covariance between traits $\mathrm{X}$ and $\mathrm{Y} ; \mathrm{GVX}_{\mathrm{X}}=$ Genotypic variance of $\mathrm{X}, \mathrm{GV}_{\mathrm{Y}}=\mathrm{Genotypic}$ variance of $\mathrm{Y}$. Confidence intervals for genetic correlation coefficients are constructed as $\mathrm{r} \pm \mathrm{z}_{(0.05)} \sigma_{\mathrm{e}}$, where $\mathrm{z}_{(0.05)}$ is the value from the standardized normal distribution table at $\mathrm{p}=0.05$ and $\sigma_{\mathrm{e}}$ is the standardized error correlation coefficient. Estimated correlation coefficients were regarded as significantly different from zero if their $95 \%$ confidence intervals did not include zero (Holland, 2006).

Path coefficient analysis: The direct and indirect effect of traits on agronomically important trait was analyzed through path coefficient analysis. This analysis was computed as suggested by Dewey and Lu (1959) with the following formula:

$$
\text { rij }=\text { Pij+ }+ \text { rikpkj }
$$

Where: rij= mutual association between the independent (i) and dependent character (j) as measured by the correlation coefficient. $\mathrm{Pij}=$ component of direct effects of independent character (i) and dependent character (j) as measured by the path coefficient and, $\mathbf{\Sigma}$ rikpkj= summation of components of an indirect effect of a given independent character (i) on the given dependent character (j) via all other independent characters $(\mathrm{k})$. The residual effect will be estimated by the formula:

$$
\sqrt{1-R^{2}}
$$

Where: $\mathrm{R}^{2}=\sum \mathrm{P}_{\mathrm{ij}} * \mathrm{r}_{\mathrm{ij}}$

pij=component of direct effects of the independent character (i) and dependent character (j) as it has been measured by the path coefficient; $r_{i j}=$ mutual association between the independent character (i) and dependent character $(\mathrm{j})$ as it was measured by the correlation coefficient. The phenotypic and genetic covariance and correlation coefficients and path coefficient analyses among pairs of traits were computed across locations using SAS version 9.2 CANDISC and IML procedures (SAS, 2011).

\section{RESULT AND DISCUSSION}

The genetic correlation for fatty acid compositions (Table 1) was shown that no significant correlation was observed for oil content with fatty acid contents and oil quality parameters and also with grain yield. Mercer et al. (1990) has also suggested that fatty acid composition should not affect the oil content of the seed. Oleic acid was significantly and positively correlated with TMUS, TUS and O/L ratio. However, oleic acid was significantly and negatively correlated with linoleic and palmitic acids, suggesting that it probably raise oleic acid content while lowering linoleic and palmitic acid contents. The highest significant negative correlation was noted for oleic and linoleic acids (r: -0.97). Grain yield was significant and positively correlated only with arachidic acid and oil yield, but negative and significantly correlated with linoleic acid.

The negative relationship between palmitic acid and oleic acid was likely due to an increased rate of palmitic acid elongation to stearic acid with rapid desaturation to oleic acid via delta-9 desaturase (Groff et al., 1996). 
Table 1. Genetic correlation of grain yield with \% oil content and fatty acids evaluated for 16 groundnut varieties across four locations.

\begin{tabular}{|c|c|c|c|c|c|c|c|c|c|c|c|c|c|c|c|c|c|}
\hline Trait & Oil & IV & Pal & Ste & Oleic & Lin & Arach & Eico & Beh & Lig & TS & TMUS & TUS & TPUS/TS & O/L & OY & GY \\
\hline Oil & 1.0 & -0.15 & -0.02 & 0.33 & 0.01 & -0.06 & 0.32 & -0.34 & 0.03 & -0.23 & 0.19 & -0.014 & -0.19 & -0.24 & -0.01 & 0.34 & 0.24 \\
\hline IV & & 1.00 & $0.57^{*}$ & -0.3 & $-0.80^{* *}$ & $0.92^{* *}$ & -0.49 & -0.03 & -0.5 & -0.05 & 0.07 & $-0.77^{* *}$ & -0.07 & $0.92^{* *}$ & $-0.86^{* *}$ & $-0.66^{* *}$ & $-0.66^{* *}$ \\
\hline Pal & & & 1.00 & 0.1 & $-0.80^{* *}$ & $0.76^{* *}$ & -0.06 & $-0.60^{*}$ & -0.33 & $-0.62^{*}$ & $0.63^{* *}$ & $-0.82^{* *}$ & $-0.63^{* *}$ & 0.27 & $-0.79^{* *}$ & -0.29 & -0.29 \\
\hline Ste & & & & 1.00 & -0.22 & 0.03 & $0.96^{* *}$ & $-0.78^{* *}$ & 0.36 & $-0.53^{*}$ & $0.78^{* *}$ & -0.27 & $-0.78^{* *}$ & $-0.56^{*}$ & -0.12 & 0.44 & 0.43 \\
\hline Oleic & & & & & 1.00 & $-0.97^{* *}$ & -0.05 & 0.49 & 0.16 & 0.38 & $-0.65^{* *}$ & $1.00^{* *}$ & $0.65^{* *}$ & $-0.53^{*}$ & $0.98^{* *}$ & 0.40 & 0.40 \\
\hline Lin & & & & & & 1.00 & -0.17 & -0.35 & -0.32 & -0.28 & 0.44 & $-0.96^{* *}$ & -0.45 & $0.71^{* *}$ & $-0.98^{* *}$ & $-0.53^{*}$ & $-0.53^{*}$ \\
\hline Arach & & & & & & & 1.00 & $-0.64^{* *}$ & $0.58^{*}$ & -0.41 & $0.71^{* *}$ & -0.1 & $-0.71^{* *}$ & $-0.71^{* *}$ & 0.07 & $0.53^{*}$ & 0.52 \\
\hline Eico & & & & & & & & 1.00 & 0.09 & $0.85^{* *}$ & $-0.83^{* *}$ & $0.55^{*}$ & $0.83^{* *}$ & 0.3 & 0.42 & -0.21 & -0.19 \\
\hline Beh & & & & & & & & & 1.00 & 0.14 & 0.32 & 0.16 & -0.32 & $-0.54^{*}$ & 0.26 & 0.32 & 0.32 \\
\hline Lig & & & & & & & & & & 1.00 & $-0.63^{*}$ & 0.43 & $0.63^{*}$ & 0.22 & 0.36 & 0.01 & 0.03 \\
\hline TS & & & & & & & & & & & 1.00 & $-0.68^{* *}$ & $-1.00^{* *}$ & -0.31 & $-0.54^{*}$ & 0.18 & 0.17 \\
\hline TMUS & & & & & & & & & & & & 1.00 & $0.68^{* *}$ & -0.48 & $0.97^{* *}$ & 0.37 & 0.37 \\
\hline TUS & & & & & & & & & & & & & 1.00 & 0.31 & $0.54^{*}$ & -0.18 & -0.18 \\
\hline TPUS/TS & & & & & & & & & & & & & & 1.00 & $-0.62^{*}$ & $-0.69^{* *}$ & $-0.69^{* *}$ \\
\hline O/L & & & & & & & & & & & & & & & 1.00 & 0.43 & 0.44 \\
\hline $\mathrm{OY}$ & & & & & & & & & & & & & & & & 1.00 & $0.99^{* *}$ \\
\hline GY & & & & & & & & & & & & & & & & & 1.00 \\
\hline
\end{tabular}

Where IV: iodine value; Pal; palmitic; Ste:steric acid; Lin: Linoleic acid; Arach: Arachidic acid; Eico:Eicosenoic acid; Beh: Behenic acid; Lig: Lignoceric acid; TS: total saturated fatty acids; TMUS: total monounsaturated fatty acids; TPUS: total polyunsaturated fatty acids; TUS: total unsaturated fatty acids; TPUS/TS: total polyunsaturated to total saturated fatty acids; 0/L: oleic to linoleic acid ratio; GY: grain yield $\left(\mathrm{kgha}^{-1}\right)$; OY: oil yield (kgha ${ }^{-1}$.

An inverse relationship between linoleic acid, O/L ratio confirmed earlier reports by Braddock et al. (1995) and O'Keefe et al. (1993).

Genetic correlation of oil content with agromorphological and oil quality traits evaluated for 16 groundnut genotypes across four locations as shown in Table 2. Oil content was significant and positively correlated with pod weight per plant (PWP) and seed weight per plant (SWP) showing that the possibility of indirect selection for oil content through PWP and SWP. Grain yield was significant and positively correlated with SWP, 100SW and OY. Similarly, OY was significant and positively correlated with SWP, 100SW and GY. Low oil quality traits like linoleic acid and TPUS were significant and positively correlated with NSPOD and TPUS/TS, but significant and negatively correlated with grain yield. High oil quality traits like oleic acid and $\mathrm{O} / \mathrm{L}$ ratio which indicate presence of monounsaturated fatty acids (responsible for oil stability or long shelf life due to reduced oxidation) were found to be positive and significantly correlated with NBP and AGBP indicating possibility of breeding for oil content trait via indirect selection through highly heritable traits. These results were in agreement with those of Shobhakruparani (1999) and Nagda et al. (2001) for days to 50 per cent flowering, Kumar et al. (1998), Sangha and Sandhu (1970) for oil yield, Abhay et al. (2002), Venkataramana (2001) for kernel yield. 
Table 2. Genetic correlation of major agro-morphological and oil traits.

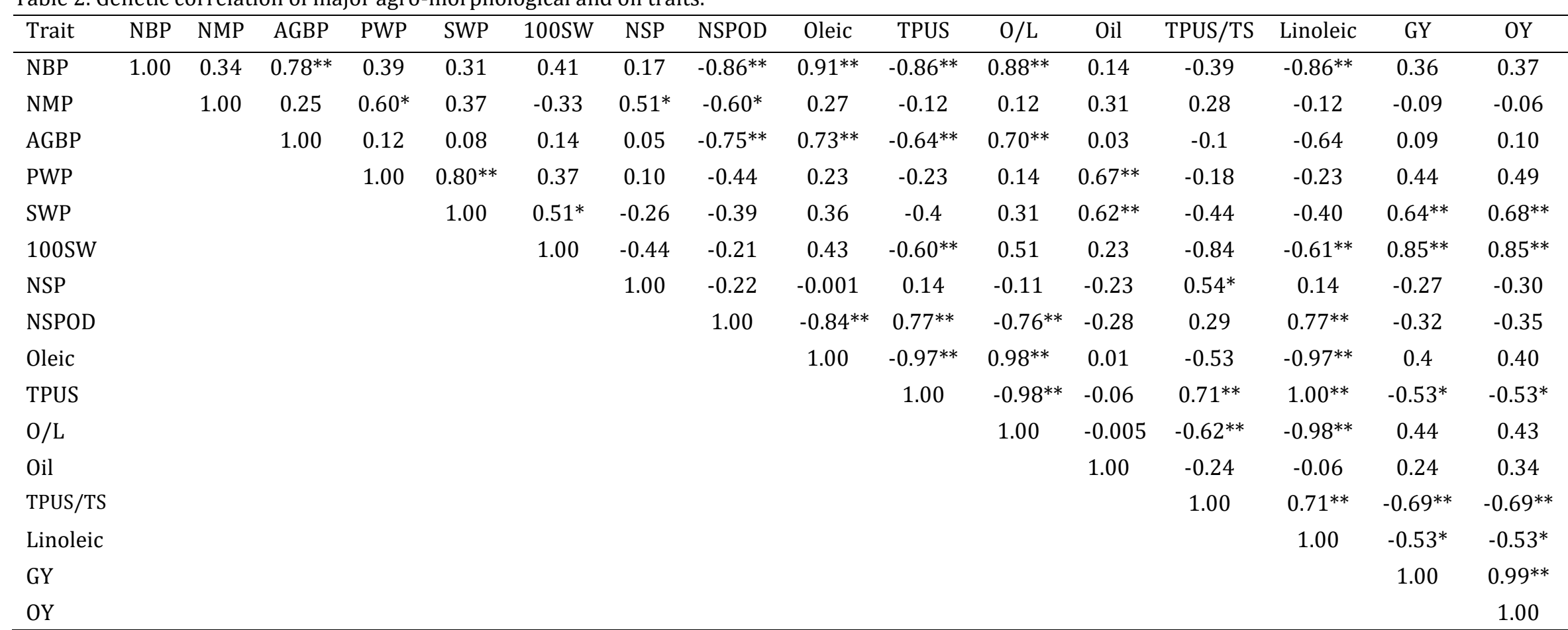

NBP: number of primary branches per plant; NMP: number of mature pods per plant; AGBP: above ground biomass per plant; PWP: pod weight per plant; SWP: seed weight per plant; 100SW:100 seed weight; NSP: number of seeds per plant; NSPOD: number of seeds per pod; TPUS: total polyunsaturated fatty acids; TPUS/TS: total polyunsaturated to saturated fatty acids ratio; GY: grain yield; OY: oil yield.

Since the correlation coefficient does not provide the true relationship amongst traits. The total genotypic correlation coefficients were further partitioned into direct and indirect effects at the genotypic level. The path analysis of oil content for agro-morphological and oil traits was shown in Table 3. In this case, in the path analysis of oil content for genetic correlations, the direct effect of the PWP trait on the oil content was smaller than the indirect effect of NMP, OY, GY and
NSPOD on oil content through PWP; in this case, the correlation value is attributed to the indirect effect of the NMP, OY, GY and NSPOD traits. In this situation, the causal indirect effect is considered for the selection processes. In a similar manner, the direct effect of SWP on oil content was also smaller than the indirect effects. Therefore, the Significant and positive genotypic correlation coefficient between SWP and oil content is explained in a larger proportion by indirect effects of OY and GY than for the direct effects of the SWP trait on oil content; this indicates that the significant and direct correlation between SWP and oil content is due, in large proportion, to the indirect influence of OY, GY, NMP and NSPOD traits.

The path analysis based on genotypic correlation in the present study was shown that breeding for oil content trait is effective through selection for high OY, GY, NMP and NSPOD. 
Table 3. Path coefficient analysis for genotypic correlations of oil content on agromorphological and oil traits, direct effect (bold) diagonal, indirect effects (off diagonal).

\begin{tabular}{lccccccccccccccc}
\hline Trait & NBP & NMP & AGBP & PWP & SWP & 100SW & NSP & NSPOD & Oleic & O/L & TPUS/TS & Linoleic & GY & OY & Oil (corrl) \\
\hline PWP & -0.14 & 0.23 & -0.04 & $\mathbf{7 . 2 2 E - 0 5}$ & -0.28 & 0.02 & 0.13 & 0.14 & -0.01 & 0.0003 & 0.04 & -0.04 & 0.31 & 0.33 & $0.67^{* *}$ \\
SWP & -0.11 & 0.14 & -0.03 & 0.002 & $\mathbf{- 0 . 0 1}$ & 0.03 & -0.35 & 0.12 & -0.01 & 0.001 & 0.10 & -0.06 & 0.44 & 0.44 & $0.62^{* *}$ \\
\hline
\end{tabular}

$\mathrm{R}^{2}=0.88 ; \mathrm{h}^{2}=0.12$

The coefficient of determination $\left(\mathrm{R}^{2}\right)$ in the path analysis of oil content for genotypic correlation indicates that $88 \%$ of the oil content variability was explained by the variables which is a good fit for the model and shows the importance of the explaining variables in the oil content definition. Estimation of direct and indirect effects of oil traits in groundnut is rarely found. However, direct and indirect effects of various quantitative traits on yield and oil content have been reported by many researchers: Tuncturk and Çiftçi (2007),
Marjanović-Jeromela et al. (2008) on Brassica species, and Baig (2017) on Soybean traits.

The path analysis of genetic correlation of $0 / L$ ratio on agro-morphological and oil traits was shown in Table 4. In this case, in the path analysis for genetic correlations, the direct effect of NBP trait on $\mathrm{O} / \mathrm{L}$ ratio was smaller than the indirect effect of AGBP, NSPOD and oleic acid traits on $0 / \mathrm{L}$ ratio; in this case, the significant correlation value between NBP and O/L ratio was attributed to the indirect effects of AGBP, NSPOD and oleic acid traits. That is breeding for high oil quality can be effective through indirect selection for high AGBP, NSPOD and oleic acid. In the path analysis of AGBP on $\mathrm{O} / \mathrm{L}$ ratio, the direct effect of AGBP on $\mathrm{O} / \mathrm{L}$ ratio was smaller than the indirect effects of NSPOD and oleic acid on the $\mathrm{O} / \mathrm{L}$ ratio; in this case, the significant and positive correlation value between AGBP and $0 / \mathrm{L}$ ratio is attributed to the indirect effects of NSPOD and oleic acid traits.

Table 4. Path coefficient analysis for genotypic correlations of O/L ratio on agro-morphological and oil traits, direct effect (bold) diagonal, indirect effects (offdiagonal).

\begin{tabular}{cccccccccccccccc}
\hline Trait & NBP & NMP & AGBP & PWP & SWP & $100 S W$ & NSP & NSPOD & GY & OY & Oil & TPUS/TS & Linoleic & Oleic & O/L \\
\hline NBP & $\mathbf{- 0 . 0 6}$ & -0.03 & 0.80 & -0.13 & -0.09 & -0.03 & -0.06 & 0.23 & -0.07 & -0.06 & 0.07 & 0.07 & 0.02 & 0.18 & $0.88^{* *}$ \\
AGBP & -2.01 & -0.18 & $\mathbf{0 . 0 3}$ & -0.38 & -0.22 & -0.09 & -0.17 & 2.02 & -0.18 & -0.16 & 0.12 & 0.18 & 0.18 & 1.39 & $0.70^{* *}$ \\
100SW & -0.68 & 0.15 & 0.90 & -0.78 & -0.92 & $\mathbf{- 0 . 0 0 3}$ & 0.98 & 0.36 & -1.10 & -0.85 & 0.69 & 1.01 & 0.11 & 0.52 & $0.51^{*}$ \\
NSPOD & 0.02 & 0.004 & -0.07 & 0.01 & 0.01 & 0.001 & 0.01 & $\mathbf{- 0 . 7 2}$ & 0.01 & 0.01 & -0.01 & -0.005 & -0.002 & -0.02 & $-0.76^{* *}$ \\
TPUSTS & 0.01 & -0.002 & -0.01 & 0.005 & 0.01 & 0.004 & -0.01 & -0.01 & 0.01 & 0.01 & -0.01 & $-\mathbf{0 . 6 1}$ & -0.002 & -0.01 & $-0.62^{* *}$ \\
Linoleic & 0.34 & 0.01 & -1.00 & 0.11 & 0.17 & 0.06 & -0.08 & -0.32 & 0.17 & 0.13 & -0.04 & -0.21 & $\mathbf{- 0 . 0 1}$ & -0.28 & $-0.98^{* *}$ \\
Oleic & -0.43 & -0.04 & 1.35 & -0.13 & -0.19 & -0.05 & 0.0003 & 0.41 & -0.15 & -0.11 & 0.01 & 0.18 & 0.05 & $\mathbf{0 . 0 3}$ & $0.98^{* *}$ \\
\hline
\end{tabular}

$\mathrm{R}^{2}=0.92 ; \mathrm{h}^{2}=0.08$

NMP: number of mature pods per plant; NBP: number of primary branches per plant; AGBP: above ground biomass per plant; PWP: pod weight per plant; SWP: seed weight per plant; NSP: number of seeds per plant; 100SW:100 seed weight; NSPOD: number of seeds per pod; IV: iodine value; TPUS/TS: total polyunsaturated to saturated fatty acids; O/L: oleic to linoleic acids ratio;GY: grain yield; OY: oil yield. 
In the path analysis of $100 \mathrm{SW}$ on $\mathrm{O} / \mathrm{L}$ ratio, the direct effect of 100SW on $\mathrm{O} / \mathrm{L}$ ratio was smaller than the indirect effects of TPUS/TS, NSP, AGBP and oil content on $\mathrm{O} / \mathrm{L}$ ratio; in this case, the significant and positive correlation value between 100SW and $\mathrm{O} / \mathrm{L}$ ratio is attributed to the indirect effects of TPUS/TS, NSP, AGBP and oil content on $0 / \mathrm{L}$ ratio traits.

Similarly, in the path analysis of oleic acid on O/L ratio, the direct effect of oleic acid on $0 / \mathrm{L}$ ratio was smaller than the indirect effects of AGBP and NSPOD on O/L ratio; in this case, the significant and positive correlation value between oleic acid and $0 / \mathrm{L}$ ratio is attributed to the indirect effects of AGBP and NSPOD traits. The path analysis has shown that breeding for high $\mathrm{O} / \mathrm{L}$ ratio can be conducted through selection for AGBP, NSPOD, NSP, oil content, TPUS/TS and oleic acid traits. The coefficient of determination $\left(\mathrm{R}^{2}\right)$ in the path analysis for genotypic correlation indicates that $92 \%$ of the $0 / \mathrm{L}$ ratio variability was explained by the variables which are a good fit for the model and shows the importance of the explaining variables in the $\mathrm{O} / \mathrm{L}$ ratio. Few reports are available about the direct and indirect effects of various oil quality traits. Chauhan et al. (2008) who reported high to moderate negative effects of palmitic, stearic, oleic, linoleic, linolenic and eicosenoic on erucic acid in Indian mustard varieties, and Siddiqui et al. (2016) who reported the direct and indirect effect of various quantitative traits on oil quality traits in linseed. From the path analysis for genotypic correlation of OY with agro-morphological and oil traits (Table 5), it was revealed that small positive direct effect was observed for most of the traits that could be due to a weaker correlation of causative traits on OY (the effect). The indirect effect of SWP mainly through oil content and NSP was found to be greater than a direct effect of SWP on OY, indicating indirect selection of high oil yielding genotype(s) through oil content and NSP might have been effective; however, both oil content and NSP have low heritability and low genetic advance. Hence, indirect selection through such low heritable trait might not be effective. The indirect effect of 100SW mainly through NSP, oil content, AGBP, NBP and TPUS/TS was found to be greater than the direct effect of 100SW on OY, indicating indirect selection of high oil yielding genotype(s) is effective through AGBP, NBP and TPUS/TS. The direct effect of the GY on the OY is less than the indirect effect of GY through NSP, oil content, TPUS/TS, and AGBP; in this case, the significant and positive correlation between GY and $\mathrm{OY}$ is attributed to the indirect effect of the NSP, oil content, TPUS/TS, and AGBP traits on OY.

Table 5. Path coefficient analysis for genotypic correlations of oil yield ( $\mathrm{kg} / \mathrm{ha})$ on agro-morphological and oil traits, direct effect (bold) diagonal, indirect effects (off diagonal).

\begin{tabular}{lcccccccccccccccc}
\hline Trait & NBP & NMP & AGBP & PWP & SWP & 100SW & NSP & NSPOD & Oleic & 0/L & Oil & TPUS/TS & Linoleic & GY & OY \\
\hline SWP & 0.19 & -0.70 & 0.46 & -3.11 & $\mathbf{- 0 . 0 9}$ & -1.48 & 1.55 & 0.13 & 0.30 & 0.19 & 6.22 & 0.28 & 0.09 & -3.43 & $0.68^{* *}$ \\
100SW & 0.53 & 1.33 & 1.74 & -3.14 & -3.50 & $\mathbf{- 0 . 0 4}$ & 5.55 & 0.15 & 0.77 & 0.66 & 4.92 & 1.14 & 0.28 & -9.84 & $0.85^{* *}$ \\
TPUS/TS & -0.01 & -0.01 & -0.02 & 0.02 & 0.04 & 0.06 & -0.08 & -0.002 & -0.01 & -0.01 & -0.06 & $\mathbf{- 0 . 6 9}$ & -0.004 & 0.10 & $-0.69^{* *}$ \\
Linoleic & -0.27 & 0.12 & -1.93 & 0.46 & 0.66 & 0.91 & -0.44 & -0.13 & -0.42 & -0.30 & -0.30 & -0.24 & $\mathbf{- 0 . 0 1}$ & 1.48 & $-0.53^{*}$ \\
GY & 40.32 & 31.64 & 94.30 & -320.0 & -377.8 & -459.6 & 293.6 & 19.69 & 63.0 & 48.88 & 440.87 & 81.43 & 21.6 & $\mathbf{- 0 . 0 0 1}$ & $0.99^{* *}$
\end{tabular}

$\mathrm{R}^{2}=0.99 ; \mathrm{h}^{2}=-0.01$

NMP: number of mature pods per plant; NBP: number of primary branches per plant; AGBP: above ground biomass per plant; PWP: pod weight per plant; SWP: seed weight per plant; NSP: number of seeds per plant; 100SW:100 seed weight; NSPOD: number of seeds per pod; IV: iodine value; TPUS/TS: total polyunsaturated to saturated fatty acids; O/L: oleic to linoleic acids ratio;GY: grain yield; OY: oil yield. 
The path analysis of genetic correlation in the present study was shown that breeding for oil yield (OY) can be conducted via selection for AGBP, NBP and TPUS/TS. The determination coefficient $\left(\mathrm{R}^{2}\right)$ in the path analysis for genotypic correlation of OY with agro-morphological and oil traits indicate that $99 \%$ of the OY variability was explained by those traits which is a good fit for the model and shows the importance of the explaining variables in the OY case. These findings were in accordance with Adeyanju et al. (2010) who reported direct and indirect effects of various oil traits on oil yield.

\section{CONCLUSION}

The biochemical analysis of oil traits will have a greater contribution to the future groundnut breeding program in Ethiopia. The present study has found that stearic acid, arachidic acid, eicosenoic acid, lignoceric acid, O/L ratio, palmitic acid, oleic acid, linoleic acid, behenic acid, total saturated fatty acids (TS), total monounsaturated fatty acids (TMUS), total polyunsaturated fatty acids (TPUS), TPUS/TS, TUS/TS and OY were more variable traits among evaluated genotypes. These traits have potential inbreeding groundnut for oil traits. However, low genetic variability for oil content and total unsaturated fatty acids (TUS) and iodine value was observed indicating that breeding for oil content should follow indirect selection through other traits due to low genetic advance for oil content trait. The present study has identified the possibility of breeding of groundnut for grain yield, high oil content, oil yield and oil quality through direct and indirect selection for agromorphological and oil traits. This study has also shown that breeding for biochemical oil traits can be conducted through selection for agro-morphological traits with low cost. Breeding for low heritable traits like oil content and oil quality traits require systematic handling of traits via indirect selection through highly heritable traits.

\section{REFERENCES}

Abhay, D., A. K. Nagada and A. Dashora. 2002. Genetic variability and character association in Spanish bunch groundnuts. Research on Crops, 3: 41640.

Adeyanju, A. O., A. Usman and S. G. Mohammed. 2010. Genetic correlation and path-coefficient analysis of oil yield and its components in castor. International Journal of Applied Agricultural Research, 5: 243-50.

Baig, K. S. 2017. Correlation and Path Analysis Studies in Soybean [Glycine $\max ($ L.) Merrill]. International
Journal of Pure \& Applied Bioscience, 5: 489-92. https://doi.org/10.18782/2320-7051.2679

Baur, F. J. and L. G. Ensminger. 1977. The association of official analytical chemists (AOAC). Journal of the American Oil Chemists' Society, 54: 171-72.

Braddock, J. C., C. A. Sims and S. F. O'Keefe. 1995. Flavor and Oxidative Stability of Roasted High Oleic Acid Peanuts. Journal of Food Science, 60: 489-93. https://doi.org/10.1111/j.13652621.1995.tb09809.x

Chauhan, J. S., K. H. Singh, S. Manuj, V. P. S. Bhadauria and A. Kumar. 2008. Studies on genetic variability and path analysis for quality traits in rapeseed mustard (Brassica species). Indian Journal of Plant Genetics, 21: 113-17.

Cruz, C. D. 2001. Programa Genes: versão Windows; aplicativo computacional em genética e estatística Federal University of Viçosa: Viçosa MG, 36570-900, Brazil.

Dewey, D. R. and K. H. Lu. 1959. A Correlation and PathCoefficient Analysis of Components of Crested Wheatgrass Seed Production. Agronomy Journal, 51: 515. https://doi.org/10.2134/agronj1959.00021962 $\underline{005100090002 x}$

Falconer, D. and T. Mackay. 1996. Introduction to quantitative genetics. In: Prentice Hall, Pearson: New Jersey, United States.

Folch, J., M. Lees and G. H. Sloane Stanley. 1957. A simple method for the isolation and purification of total lipides from animal tissues. Journal of Biological Chemistry, 226: 497-509.

Groff, J. L., S. S. Gropper and S. M. Hunt. 1996. Lipids: In Advanced Nutrition and Human Metabolism West Publishing: St. Paul, MN, United States.

Hallauer, A. R., M. J. Carena and J. d. Miranda Filho. 2010. Quantitative genetics in maize breeding lowa State University Press: Ames, IA, United States.

Holland, J. B. 2006. Estimating Genotypic Correlations and Their Standard Errors Using Multivariate Restricted Maximum Likelihood Estimation with SAS Proc MIXED. Crop Science, 46: 642. https://doi.org/10.2135/cropsci2005.0191

Holland, J. B., W. E. Nyquist and C. T. Cervantes-Martínez. 2010. Estimating and Interpreting Heritability for Plant Breeding: An Update Plant Breeding Reviews. John Wiley \& Sons, Inc. pp. 9-112.

Kumar, R., J. Ghosh, J. N. Sah and R. Kumar. 1998. 
Variability and correlation studies in mutant cultures of groundnut. Journal of Applied Biology \& Biotechnology, 8: 20-23.

Marjanović-Jeromela, A., R. Marinković, A. Mijić, Z. Zdunić, S. Ivanovska and M. Jankulovska. 2008. Correlation and path analysis of quantitative traits in winter rapeseed (Brassica napus L.). Agriculturae Conspectus Scientificus, 73: 13-18.

Mercer, L. C., J. C. Wynne and C. T. Young. 1990. Inheritance of Fatty Acid Content in Peanut Oil. Peanut Science, 17: 17-21. https://doi.org/10.3146/i0095-3679-17-1-7

Nagda, A. K., A. Dashora and D. K. Jain. 2001. Character association in parents and hybrids of groundnut (Arachis hypogaea L.). Crop Research Hisar - The Pherobase, 22: 463-68.

O'Keefe, S. F., V. A. Wiley and D. A. Knauft. 1993. Comparison of oxidative stability of high- and normal-oleic peanut oils. Journal of the American Oil Chemists' Society, 70: 489-92. https://doi.org/10.1007/bf02542581

Sangha, A. S. and R. S. Sandhu. 1970. Genetic variability and correlation studies in groundnut (Arachis hypogaea L). Journal of Research-Punjab Agricultural University, 7: 143-50.

SAS. 2011. SAS enterprise guideSAS Institute. Cary, North Carolina, United States.
Shobhakruparani, K. 1999. Genetic variability and character association analysis in confectionery groundnut (Arachishypogaea L.) genotypes, University of Agricultural Sciences. Dharwad, India.

Siddiqui, A., S. Shukla, A. Rastogi, A. Bhargava, A. Niranjan and A. Lehri. 2016. Relationship among phenotypic and quality traits in indigenous and exotic accessions of linseed. Pesquisa Agropecuária Brasileira, 51: 1964-72. https://doi.org/10.1590/s0100204x2016001200007

Slover, H. T. and E. Lanza. 1979. Quantitative analysis of food fatty acids by capillary gas chromatography. Journal of the American Oil Chemists' Society, 56: 933. https://doi.org/10.1007/bf02674138

Tuncturk, M. and V. Çiftçi. 2007. Relationships between yield and some yield components in rapeseed (Brassica napus ssp. oleifera L.) cultivars by using correlation and path analysis. Pakistan Journal of Botany, 39: 81.

Venkataramana, P. 2001. Variability and correlation studies in groundnut. Crop Research Hisar - The Pherobase, 21: 81-83. 